Children and young people are shaped by and shape the environments in which they live. An ecological perspective requires child health professionals to develop a range of strategic responses at individual, family, neighbourhood, regional and national levels. ${ }^{3}$ The models for this approach to improving the health of children and youth have been outlined in the strategic plan 'Health Gain for Children and Youth of Central Sydney' (developed by the Central Sydney Area Health Service over the past two years) ${ }^{4}$ Some of these programs have been implemented in some health areas such as South Western Sydney Area Health Service.

If the outlined challenges to the continued improvement of child health in NSW are to be met, and if the health goals and targets for Australian children are to be achieved, health care services in NSW will need to refocus their attention to the needs of children, to identify and implement more evidence-based strategies, and to emphasise population-based illness-prevention and health- promotion programs. If the outcomes are to be attained, an effective population-based approach to child health needs to become as essential a part of health services as clinical paediatrics.

\section{REFERENCES}

1. Birrell B, Maher C, Rapson V. Welfare dependence in Australia. People and Place 1997; 5: 68-77.

2. Child, Adolescent and Family Health Service. Health Goals and Targets for Australian Children and Youth. Canberra: Child, Adolescent and Family Health Service and Department of Community Services and Health, 1992.

3. Role of the Faculty (Chapter) of Community Child Health [discussion paper]. Sydney: Faculty (Chapter) of Community Child Health, Australian College of Paediatrics, 1997.

4. Health Gain for Children and Youth of Central Sydney [strategic plan]. Sydney: Sydney Health Services Planning Unit and Division of Population Health, Central Sydney Area Health Service, 1996. H:

\title{
CHILD HEALTH NOW! THE STATE OF CHILDREN'S HEALTH: HISTORICAL CONTEXTS AND CURRENT DEVELOPMENTS
}

\section{Elisabeth Murphy}

Clinical Adviser, Health Services Policy Branch

Caroline Wraith

Senior Policy Analyst, Health Services Policy Branch

$T^{n}$ he NSW Health Department is currently developing a comprehensive child health policy, which is nearing completion. It will provide a framework for the health system to address the health care needs of children and provide child-focused and developmentally ap propriate health services. This article provides an overview of the international and national contexts supporting this development and highlights both a number of current state initiatives and future directions in child health.

\section{INTERNATIONAL CONTEXT}

The origins of an international agenda for children emerged just after the second world war. In 1948 the Universal Declaration of Human Rights was proclaimed, and in 1959 the special needs of children were addressed by the United Nations Declaration on the Rights of the Child. One outcome of the International Year of the Child in 1979 was the push for the United Nations Convention on the Rights of the Child which was achieved 10 years later. ${ }^{1}$ The Convention was adopted by the United Nations (UN) on 20 November 1989 and was ratified faster than any other convention in the history of the United Nations.
It consolidated into international law the existing provisions of over 100 declarations and treaties.

The Convention led to the World Summit for Children (1990), at which the United Nations World Declaration on the Survival, Protection and Development of Children ${ }^{2}$ was developed and an international commitment given to a plan of action. ${ }^{3}$ The World Summit for Children was the first ever truly global gathering of world leaders. If the goals of the Declaration are met then it is estimated that the lives will be saved of 50 million of the 150 million children who are otherwise projected to die of preventable causes over this decade. ${ }^{4}$ New problems such as child abuse, sexual exploitation, drug-related problems and inter-country adoptions are also addressed in the Declaration. For the first time, the role of the child as a consumer is acknowledged and the right of that child to be involved and participate in decision making on matters that affect his or her own interests is emphasised.

\section{NATIONAL CONTEXT}

Australia signed the United Nations Convention on the Rights of the Child in August 1990 and ratified it in December 1990. Some of the concerning health issues for Australian children include immunisation and poor infant mortality rates in the Aboriginal population to more complex social problems such as child abuse and youth suicide. 
The publication of Health Goals and Targets for Australian Children and Youth in 1992 represented the first attempt to determine common aims and objectives for the development and provision of child health services across Australia. ${ }^{5}$ As such, it was an important starting point for planning to improve the health outcomes for Australian children. This document recommended five goals:

1. Reduce the frequency of preventable mortality: in particular, mortality from injury, suicide and sudden infant death syndrome, and Aboriginal infant mortality.

2. Reduce the impact of disability, including reductions in the occurrence of new disability and the impact of established disabilities:

focusing on congenital abnormalities, low birthweight, prematurity, chronic illness, intellectual disability, physical disability and learning disorders.

3. Reduce the incidence of vaccine-preventable diseases.

4. Reduce the impact of conditions occurring in adulthood which have their early manifestations in childhood or the teen years:

in particular, conditions associated with suboptimal nutrition and/or fitness (for example, cardiovascular disease, diabetes mellitus and osteoporosis), alcohol and tobacco use, unprotected sexual activity (for example, unplanned pregnancy, sexually transmitted diseases including Chlamydia trachomatis infection, hepatitis B and HIV-AIDS) and excessive exposure to sunlight.

5. Enhance family and social functioning: including parenting and the well-being of children and young people, child abuse and neglect, importance of adequate housing and family income, importance of education for development, youth employment, enhancing physical and social environments.

The final goal links with all the other goals listed.

Health Goals and Targets for Australian Children and Youth included a strong recommendation that there should be a national plan of action to address the health needs of young people. This was addressed by the subsequent development of The Health of Young Australians: a National Health Policy for Children and Young People in 1995. ${ }^{6}$ This policy was endorsed by all the Australian Health Ministers and represented the first formal commitment by Australian governments to work cooperatively to promote, maintain and improve the health status of all Australian children. It also recommended that a parallel process of policy development be undertaken at the State level.

A national framework for key areas of action and strategic directions has now been put in place. The seven key areas of this policy are:

1. Promotion of healthy supportive environments for children and young people through appropriate policies, programs and services by all levels of government and the community.

2. Provision of health services that have both a focus on the needs of consumers and a commitment to participation of young people and families in decisions about health and health care.

3. Development of a balanced approach at all levels of government between those strategies that actively promote good health through environmental and behavioural change and those that provide care and treatment for ill health.

4. Reduction of inequities in the availability of, and access to, the range of health services appropriate to the needs of young Australians.

5. Greater coordination and collaboration within the health sector and between health and other sectors through the development of cooperative strategies to improve the health of children and young people.

6. Regular monitoring of the health of children and young people complemented by research targeting priority issues for the health of children and young people.

7. Development of a workforce with the skills and knowledge to work effectively in the maintenance and enhancement of the health of young Australians together with increased emphasis on the training needs of people whose work relates to the health of children and young people.

In 1997 an implementation plan, The National Health Plan for Young Australians: An Action Plan to Protect and Promote the Health of Children and Young People, was released. ${ }^{7}$

\section{NSW INITIATIVES}

In response to these international and national policy developments, the NSW Health Department released to wide consultation Caring for Health, Caring for Children: a Discussion Paper Towards the Development of a Child Health Policy for NSW in $1996 .^{7}$ This policy is currently being finalised and will promote the development of prevention, early-intervention and health-promotion strategies to address preventable health problems,. It will also seek to improve the accessibility, appropriateness and quality of the health services provided to children.

To inform the development of this child health policy, and using the structure of the Health Goals and Targets for Australia Children and Youth, high-priority health issues were identified for the children of NSW. Current activities in the health system addressing these issues were then identified. The following are examples of these activities. Many show how collaboration, both within the health system and across sectors, is an important strategy for improving the health of children. 
Health goal: Reduce preventable premature mortality

- The most successful injury prevention activities are those that concentrate on creating a safe environment for children. The 'Hot Water Burns Like Fire' campaign was a partnership between the NSW Health Department, plumbing and housing industry groups and key child health advocates such as Kidsafe NSW. It focused mainly on encouraging householders to reduce the temperature of their hot water delivery to bathrooms. The campaign used a full range of media and industry education mechanisms. The first phases of the campaign have been significantly successful, with a 30 per cent decline in serious hot tap water scalds admissions $(10+$ days) and an 11 per cent decline in less serious cases.

- Sudden infant death syndrome (SIDS) is the most common cause of death in the first year of life. Since the introduction of the 'Reducing the Risks' campaign in 1991 the incidence of SIDS has declined significantly in NSW, with deaths decreasing from 174 in 1987 to 71 in 1996. The success of this campaign has been attributed to effective partnerships among the public, the Sudden Infant Death Association, researchers and health professionals. These partnerships have enabled sound evidence to support decisions, wide participation in decision making and the provision of consistent information to the public.

\section{Health goal: Reduce the impact of disability}

- Low birthweight, principally due to preterm birth, and birth defects are major causes of premature death and childhood disability. All births in NSW are registered in the Midwives Data Collection from which annual reports are prepared. These reports include information on rates of low birthweight and preterm birth by maternal age, Aboriginality, maternal residence and type of hospital. These data and issues of concern are considered by the Minister's Maternal and Perinatal Committee and, where appropriate, recommendations are made regarding clinical care. The Committee also has the Perinatal Outcomes Working Party, which can examine issues requiring further study.

- Asthma is the most common chronic illness in childhood and a principal cause of hospitalisation. Evidence suggests that prevalence rates of childhood asthma have increased in Australia over the last decade. The NSW Asthma Health Improvement Project, commenced in 1995, involves the collaboration of health professionals, consumers and government. An evidence-based review has been conducted of strategies to prevent the development of asthma and for preventing exacerbations. Asthma and the Environment: Perspectives on the Prevention of Asthma has been produced by the NSW Health Department to inform health professionals and consumers. ${ }^{9}$
- The NSW Early Intervention Coordination Project (EICP) is jointly funded by the Department of Health, the Department of Ageing and Disability, the Department of Education and Training, and the Department of Community Services. It is a statewide project to improve the coordination of early intervention services provided for families with young children who have developmental delays or disabilities. The project has resulted in these departments and the nongovernment sector working collaboratively to ensure that the range of services required by families of young children with developmental delays or disabilities are coordinated, accessible and accountable. A recent external evaluation of the Project found that 80 per cent of EICP service users received early intervention services within two months or less of having their needs identified, and of these, 50 per cent received services in less than one month.

Health goal: Reduce the incidence of vaccinepreventable diseases

- Universal immunisation is a major preventive health strategy for children. It is a simple, safe and effective way of protecting children (and adults) from harmful infection. Since 1994, parents in NSW have been requested, under the NSW Public Health Act, to provide evidence of age-appropriate immunisation to child care facilities and present an immunisation certificate at the time of school enrolment. In the event of outbreaks of infectious diseases, children who are not immunised may be excluded from child care facilities and schools.

Health goal: Reduce the impact of conditions occurring in adulthood which have their early manifestations in childhood

- Epidemiological evidence suggests that sun exposure in childhood is particularly important in causing skin cancer, particularly melanoma. The NSW Health Department worked in partnership with the NSW Cancer Council to develop and launch a mass media campaign for the summer of 1997-98. This campaign specifically targeted parents and carers of children aged 0-11 years. The campaign also targeted organisations and individuals outside the home environment who make decisions affecting the sun protection of children: for example, staff of child care centres, preschools and schools.

Health goal: Enhance family and social functioning

- The Interagency Schools As Community Centres Project was established in June 1995 and aims to prevent disadvantage for children entering school by providing integrated services for families with children under five years of age in disadvantaged communities. The project is a joint initiative of the Departments of Education and Training, Health, Community Services 
and Housing. The Project works with families to encourage and support them in their parenting role, actively promotes community involvement in the provision of services for children, and encourages and assists parents to obtain access to existing mainstream services in the community. The Project has been successful in promoting access to services for disadvantaged groups, including Aboriginal families, and provides an appropriate facility for the development of many intersectoral programs targeting children under five years and their families.

- Each Area Health Service has a child protection coordinator and has recently been funded to develop new services and appoint additional staff to provide counselling and support to children who have been physically or emotionally abused or neglected and their families. Services are guided by the NSW Health Department's Child Protection Policy and Procedure Manual. ${ }^{10}$

\section{CHILD HEALTH: FUTURE DIRECTIONS}

In NSW child health services have a long and proud history of being both community-health and hospital based. However, these differing origins have meant that. to date. as child health services have expanded and new services developed, they have become increasingly disparate. Early childhood health services, school health services, health promotion, public health, general practice, paediatric wards, outpatient and specialised paediatric hospitals all provide preventive, early intervention and/or treatment services for children.

The development of the child health policy for NSW will provide a coordinated framework for the health system to provide child-focused and developmentally appropriate health services that address the health care needs of children. It will also support the role of the health sector of advocate for the needs of children and in promoting initiatives that will contribute to more-comprehensive and better-coordinated prevention and early intervention programs. Many of the health problems experienced by today's children reflect the complex interactions between children and their families and their social, economic and cultural environments.

Improving the health of children is integral to improving the health of adults in NSW. Many adult diseases have their origins in childhood and many health behaviours are established at this time. A focus on prevention and early health interventions that address the needs of children, if effectively provided, will deliver long-lasting health outcomes for all people in NSW.

Increased coordination of activity across the health system is needed if we are to maximise the opportunities to improve the health of children. Greater collaboration among hospital paediatric services, community child health services, general practice, public health and health promotion activities focused on children will be encouraged. Partnerships with other government departments, non-government organisations and the community will be promoted as a vehicle for the development of more effective programs across health, education and welfare services to address the needs of children and support their families and the communities in which they live.

\section{REFERENCES}

1. Convention on the rights of the child. In: First call for children. New York: UNICEF, 1990.

2. World declaration on the survival, protection and development of children. In: First call for children. New York: UNICEF, 1990.

3. Plan of action for implementing the world declaration on the survival, protection and development of children. In: First call for children. New York: UNICEF, 1990.

4. Grant JP. Address to Child Health 2000 World Congress, Vancouver, BC, 1992. New York: UNICEF.

5. Health goals and targets for Australian children and youth. Project Report. Canberra: Department of Health, Housing and Community Services, September 1992.

6. Department of Health and Human Services. The health of young Australians: a national health policy for children and young people. Canberra: Australian Government Publishing Service, 1995.

7. Department of Health and Family Services. The national health plan for young Australians: an action plan to protect and promote the health of children and young people. Canberra: Australian Government Publishing Service, 1997.

8. caring for health, caring for children: a discussion paper towards the development of a child health policy for NSW. Sydney: NSW Health Department, August 1996.

9. Asthma and the environment: perspectives on the prevention of asthma. Sydney: NSW Health Department, 1997.

10. Child protection policy and procedure manual. Sydney: NSW Health Department, March 1997. 